\title{
PAR-1 and the microtubule-associated proteins CLASP2 and dynactin-p50 have specific localisation on mouse meiotic and first mitotic spindles
}

\author{
Catherine A Moore and Magdalena Zernicka-Goetz \\ University of Cambridge, The Wellcome Trust/Cancer Research UK Gurdon Institute of Cancer and Developmental \\ Biology, Tennis Court Road, Cambridge CB2 1QR, UK and Department of Genetics, Downing Street, Cambridge \\ CB2 3EH, UK
}

Correspondence should be addressed to M Zernicka-Goetz; Email: mzg@mole.bio.cam.ac.uk

(C A Moore is now at Centre for Developmental and Biomedical Genetics, Department of Biomedical Science, University of Sheffield, Firth Court, Western Bank, Sheffield S10 2TN, UK)

\begin{abstract}
The site of second meiotic division, marked by the second polar body, is an important reference point in the early mouse embryo. To study its formation, we look at the highly asymmetric meiotic divisions. For extrusion of the small polar bodies during meiosis, the spindles must be located cortically. The positioning of meiotic spindles is known to involve the actin cytoskeleton, but whether microtubules are also involved is not clear. In this study we investigated the patterns of localisation of microtubule regulatory proteins in mouse oocytes. PAR-1 is a member of the PAR (partitioning-defective) family with known roles in regulation of microtubule stability and spindle positioning in other model systems. Here we show its specific localisation on mouse meiotic and first mitotic spindles. In addition, the microtubule-associated proteins CLASP2 (a CLIP associating protein) and dynactin-p50 are found on kinetochores and a subset of microtubule-organising centres. Thus we show specific localisation of microtubule regulatory proteins in mouse oocytes, which could indicate roles in meiotic spindle organisation.
\end{abstract}

Reproduction (2005) 130 311-320

\section{Introduction}

Mammalian female meiotic divisions are asymmetric, producing a large mature oocyte and small polar bodies. To achieve this asymmetry and thus limit loss of maternal supplies from the gamete, the meiotic spindles migrate to the cortex of the cell prior to division. The positioning of these spindles will determine the sites of polar body extrusion, which will later affect the orientation of embryonic cleavage (Plusa et al. 2002, 2005, Piotrowska-Nitsche \& Zernicka-Goetz 2005).

The importance of actin in positioning the first meiotic spindle is unequivocal (Longo \& Chen 1985, Leader et al. 2002), but the possibility of microtubule-actin interactions has not been investigated. Although microtubuledepolymerisation drugs still allow movement of the chromosomes to the cortex, the integrity of the chromosome mass is not maintained in the absence of a spindle (Maro et al. 1986, Van Blerkom \& Bell 1986), and the fact that the direction of spindle migration in untreated oocytes is always along the long axis of the spindle (Verlhac et al. 2000) suggests that the spindle microtubules (MTs) do play a role in deciding the direction of movement. Moreover, in other systems where spindle migrations and rotations have been studied in detail, interactions between the spindle MTs and the cortex play an important role (for reviews see Segal \& Bloom 2001, Dujardin \& Vallee 2002, Kaltschmidt \& Brand 2002, Ahringer 2003). Such interactions during positioning of the mouse meiotic spindle have been discounted because of the belief that there are no astral MTs emanating from this spindle (Verlhac et al. 2000, Maro \& Verlhac 2002), although previously astral MTs were seen by electron microscopy (Szöllösi et al. 1972). Recent work investigating centrosomal and spindle structure dependence on culture conditions indeed reveals some astral MTs on meiotic spindles (Sanfins et al. 2003, Sanfins et al. 2004) and after metaphase II (MII) oocyte activation (Albertini \& Barrett 2004).

Some progress has been made towards understanding the molecular details of the actin-dependent spindle migration. Roles for myosin II isoforms (Simerly et al. 1998), fodrin (Schatten et al. 1986a), formin-2 (Leader et al. 2002) and the two mammalian PAR-6 homologues 
mPARD6a and mPARD6b (partitioning-defective family members; Gray et al. 2004, Vinot et al. 2004) have been proposed, but the interactions between the chromosomes, or the spindle, and the cortex have not been characterised. Here we present studies of proteins proposed as candidate factors involved in possible microtubule-dependent positioning of the first mouse meiotic spindle.

Candidates were investigated whose homologues have known roles in spindle orientation or organisation in other model systems: PAR-1, CLASP2 and dynactin. PAR-1 is a kinase and is part of the partitioning-defective family. Mammalian homologues are also known as ELKL-motif kinases (EMKs) or microtubule affinity-regulating kinases (MARKs) (Inglis et al. 1993, Drewes et al. 1997, Ebneth et al. 1999, Trinczek et al. 2004). The roles of PAR-1 in cell polarisation and spindle orientation have been shown in several model systems (for reviews see Ahringer 2003, Macara 2004). CLASP2 is a CLIP (cytoplasmic linker protein)-associating protein with a role in stabilising MTs (Akhmanova et al. 2001), and possibly in providing capture sites to link MTs to the membrane (for reviews see McNally 2001, Schuyler \& Pellman 2001, Mimori-Kiyosue \& Tsukita 2003). The involvement of dynactin in spindle orientation has been demonstrated in several species (Busson et al. 1998, Skop \& White 1998, O'Connell \& Wang 2000, Sheeman et al. 2003).

In this report we show specific localisation of PAR-1, CLASP2 and dynactin on mouse meiotic spindles. In addition, we have found fixation conditions allowing visualisation of astral MTs on meiotic spindles. Thus our results further support the proposition that MTs may be important in meiotic spindle positioning.

\section{Materials and Methods}

\section{Oocyte and embryo collection and culture}

All embryos and oocytes were from F1 (C57BL/ $6 \times \mathrm{CBA})$ mice. Oocytes arrested at germinal vesicle (GV) stage were collected from females by ovarial puncture in M2 medium (Nagy et al. 2003). To obtain metaphase I (MI) oocytes, GV stage oocytes were cultured until GV breakdown and then for a further 6-7 h, in M16 (Nagy et al. 2003) supplemented with $5 \%(\mathrm{v} / \mathrm{v})$ fetal calf serum at $37.5^{\circ} \mathrm{C}$ and $5 \% \mathrm{CO}_{2}$. Embryos, and oocytes arrested at MII, were collected from females induced to superovulate by intraperitoneal injection of $10 \mathrm{IU}$ pregnant mare serum gonadotrophin (Intervet UK Ltd, Milton Keynes, UK) followed $48 \mathrm{~h}$ later by $7.5 \mathrm{IU}$ human chorionic gonadotrophin (hCG; Intervet). Fertilised embryos were obtained following mating with F1 males. MII oocytes and zygotes were collected from oviducts approximately 14 and $19 \mathrm{~h}$ after hCG injection respectively into phosphate-buffered saline (PBS) containing $200 \mathrm{IU} / \mathrm{ml}$ hyaluronidase, then transferred to M2 medium. Embryos undergoing the first and second mitotic divisions were collected from oviducts at approximately 27 and $51 \mathrm{~h}$ after hCG injection respectively, and cultured until the group started to divide, in KSOM medium (Speciality Media, Inc., Lavallette, NJ, USA) supplemented with amino acids and $4 \mathrm{mg} / \mathrm{ml}$ bovine serum albumin (BSA) at $37.5^{\circ} \mathrm{C}$ and $5 \% \mathrm{CO}_{2}$.

\section{RT-PCR}

Pools of five to fifteen embryos or oocytes were frozen at $-80^{\circ} \mathrm{C}$ in PBS. Two methods were used for RT-PCR. Similar results were obtained by both methods and with two sets of primers for each gene. All products were of the expected size and were checked by sequencing, and negative controls for both RT and PCR were performed.

\section{Method A}

mRNA was extracted using Dynabeads mRNA DIRECT Micro Kit (Dynal Biotech, Oslo, Norway), mRNA not eluted from beads. RT was performed at $42^{\circ} \mathrm{C}$ for $30 \mathrm{~min}$, using the bead oligo $(\mathrm{dT})_{25}$ as primer and a 2:1 mix of AMV and M-MuLV reverse transcriptases (Roche Diagnostics $\mathrm{GmbH}$, Mannheim, Germany). Gene-specific PCR was performed using Taq polymerase (Roche) and a BioRad MJ Research PTC-100 Peltier thermal cycler (Bio-Rad, Hemel Hempstead, UK). Up to 45 cycles of a touchdown PCR (annealing temperature decreasing from $72{ }^{\circ} \mathrm{C}$ to $\left.60^{\circ} \mathrm{C}\right)$ were used.

\section{Method B}

RT-PCR was performed using SuperScript one-step RT-PCR kit with platinum Taq (Invitrogen Paisley, UK) and 40-44 cycles of PCR (optimised for each primer pair so that a product was just detectable), with annealing temperature of $55^{\circ} \mathrm{C}$. This method uses gene-specific primers for the RT step as the RT and PCR proceed without interruption.

\section{Primers}

The following primers were used: EMK 5'-CGAGTGGAGACGCTCAGACC- $3^{\prime}$ and 5'-CTCCCACTGCACAAAGTTCTCG-3', accession number NM_007928, fragment amplified 2041-2298; also EMK 5'-GCATGAGGACGATGAGCT-3' and 5'-GTAGGAATTCGAGGTGGGAATGG-3', accession number NM_007928, fragment amplified 10141353; CLASP2 5'-ACCTAAAACACCTGGGAATCCTG- ${ }^{\prime}$ and 5'-AAAAGCAATCATACTGTGCGGC-3', accession number XM_135174, fragment amplified 258-556; also CLASP2 5'-CCTTGGGGATAAAGAGCCTAC-3' and $5^{\prime}-$ TAGACCTGGGAAACCGCAG-3', accession number XM_135174, fragment amplified 3453-4115; $\beta$-actin 5'GAAGTGTGACGTTGACATCCG-3' and 5'-ACTTGCGGTGCACGATGGAGG-3', accession number X03672, fragment amplified 929-1200.

\section{Fixation and immunostaining}

Before fixation, the zonae pellucidae were removed by a brief incubation in acidic Tyrode's solution. Fixation was 
performed in $3.7-5 \%(\mathrm{w} / \mathrm{v})$ paraformaldehyde plus $0.03-$ $0.1 \%(\mathrm{v} / \mathrm{v})$ Triton $\mathrm{X} 100$, up to $0.3 \%(\mathrm{v} / \mathrm{v})$ Tween 20 , up to $0.15 \%(\mathrm{v} / \mathrm{v})$ glutaraldehyde and up to $2 \%(\mathrm{w} / \mathrm{v})$ sucrose, at $37^{\circ} \mathrm{C}$ for $20-40 \mathrm{~min}$ in agar-coated dishes. Preservation of microtubules was particularly sensitive to detergent concentration and temperature and exact parameters needed re-optimisation for each set of experiments. For immunostaining, all steps were carried out in agar-coated 96-well plates, oocytes/embryos being moved between solutions by mouth pipetting. After fixation, oocytes and embryos were permeabilised in $0.25-0.5 \%$ Triton X100 for 20 min at room temperature, aldehyde groups were quenched with $\mathrm{NH}_{4} \mathrm{Cl}$ at $2.6 \mathrm{mg} / \mathrm{ml}$ for $10 \mathrm{~min}$ at room temperature, blocking was in $3 \%(\mathrm{w} / \mathrm{v})$ BSA in PBS for $30 \mathrm{~min}$ at room temperature. Primary and secondary antibodies were diluted in $3 \%$ BSA/PBS and incubations were at $4{ }^{\circ} \mathrm{C}$ overnight or at least $1 \mathrm{~h}$ at room temperature. DNA was stained with 2-5 $\mu \mathrm{M}$ TOTO-3 (Molecular Probes, Eugene, Oregon, USA) in PBS, for $10 \mathrm{~min}$ at room temperature. Oocytes/embryos were mounted on coverslips coated with $0.01 \%(\mathrm{w} / \mathrm{v})$ poly-L-lysine, in Vectashield (Vector Laboratories Inc. Peterborough, UK), and viewed with an upright confocal microscope (Bio-Rad Radiance 2000 confocal mounted on a Nikon E800 microscope). Images were created using LaserSharp software (Bio-Rad) with filter settings adjusted to minimise bleedthrough between channels, and Z-series were saved as multiple TIFF files.

\section{Western blotting}

Embryos/oocytes were collected in PBS and frozen at $-80^{\circ} \mathrm{C}, 150$ were used per lane. Mouse brain extract was prepared by homogenisation in ice-cold PBS with protease inhibitors, followed by boiling in Laemmli buffer (Sigma, Poole, Dorset, UK). Oocyte/embryo samples were thawed in Laemmli buffer and boiled for 3 min prior to loading. Proteins were separated by SDS-PAGE (7.5\% acrylamide) using a Mini-Protean 3 electrophoresis system (Bio-Rad), then transferred to Hybond ECL nitrocellulose membrane (Amersham Pharmacia Biotech, Amersham, Bucks, UK) using a mini trans-blot transfer cell (Bio-Rad) for immersion transfer. Membranes were blocked overnight at $4{ }^{\circ} \mathrm{C}$ in $5 \%$ dried milk in Tris-buffered saline. Antibody incubations were performed at room temperature for $1 \mathrm{~h}$. Horseradish peroxidase-conjugated secondary antibodies were detected with the ECL + Plus western blotting system (Amersham Pharmacia Biotech).

\section{Antibodies}

\section{Primary antibodies}

The following primary antibodies were used: mouse antidynactin p50 from BD Transduction Laboratories (BD Biosciences Pharmingen, Oxford, UK), used at 1:40 for immunostaining and 1:250 for western blotting; CLASP2 no. 2358 rabbit antiserum was a gift from A Akhmanova (Akhmanova et al. 2001), used at 1:300 for immunostain- ing and 1:500 for western blotting; rabbit anti-EMK was a gift from T V Kurzchalia (Böhm et al. 1997), used at 1:50 for immunostaining and 1:1000 for western blotting; tubulin rat monoclonal clone YL1/2 from Abcam (Cambridge, UK), used at 1:1000 for both immunostaining and western blotting; rabbit anti-GFP (green fluorescent protein) from Abcam used at 1:4500 for western blotting. Controls were ChromPure purified whole molecule mouse IgG (Jackson ImmunoResearch Laboratories, Stratech Scientific Ltd, Soham, Cambs, UK) and rabbit pre-immune serum as appropriate.

\section{Secondary antibodies}

The following secondary antibodies were used: AlexaFluor 488 goat anti-rat $\lg \mathrm{G}(1: 600)$, AlexaFluor 488 donkey antimouse IgG (1:500) and AlexaFluor 568 goat anti-mouse (1:500) (Molecular Probes); rhodamine Red-X-conjugated Fab fragment donkey anti-rabbit IgG (1:200), FITC-conjugated Fab fragment donkey anti-rabbit (1:400) and Texas Red dye-conjugated Fab fragment goat anti-rat $\operatorname{lgG}(1: 500)$ (Jackson ImmunoResearch Laboratories); horseradish peroxidase-conjugated anti-rat, anti-mouse and anti-rabbit (1:10 000) (Santa Cruz Biotechnology, Santa Cruz, CA, USA).

\section{Overexpression of dynactin-p50}

p50-T7, a plasmid containing human dynactin-p50 (accession number NM_006400), was a gift from T Hyman (Wittmann \& Hyman 1999). In order to produce a stable mRNA in vitro, with an N-terminal GFP tag, p50 was transferred into pßGFP/RN3P (Zernicka-Goetz et al. 1996, 1997). p50 was amplified using the following primers: $5^{\prime}$-CGCGTCGACGCGGACCCTAAATACG-3' and 5'-CGAAGCTTT CACTTTCCCAGCTTCTTCATC-3'. The PCR product was cut with HindIII, blunted with Klenow polymerase (Roche)

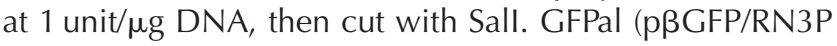
with an extra multiple cloning site) was cut with Stul then Sall and ligated to the p50 PCR product. The fusion construct was sequenced to check the sites of ligation and fidelity of PCR. The resulting plasmid was linearised with Sfil and in vitro transcription was performed with T3 polymerase using the mMessage mMachine kit for production of capped RNA (Ambion, Austin, Texas, USA). The mRNA was phenol/chloroform-extracted and precipitated with isopropanol, washed in $70 \%$ ethanol then resuspended in nuclease-free water for injection at $1 \mu \mathrm{g} / \mu \mathrm{l}$. Microinjection of oocytes was performed using negative capacitance as previously described (Weber et al. 1999).

\section{Results}

\section{EMK (PAR-1), CLASP2 and dynactin are present throughout oocyte maturation and in early embryos}

EMK (a PAR-1 homologue) was expressed at all stages from GV stage oocyte to blastocyst, and CLASP2 mRNA was 
A

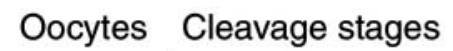

EMK $\beta$-actin \begin{tabular}{lll|lllll} 
GV & I & $\|$ & 1 & 2 & 4 & 16 & B
\end{tabular}

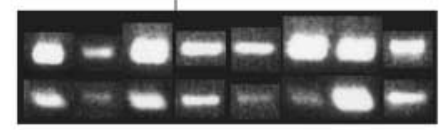

CLASP2

$\beta$-actin
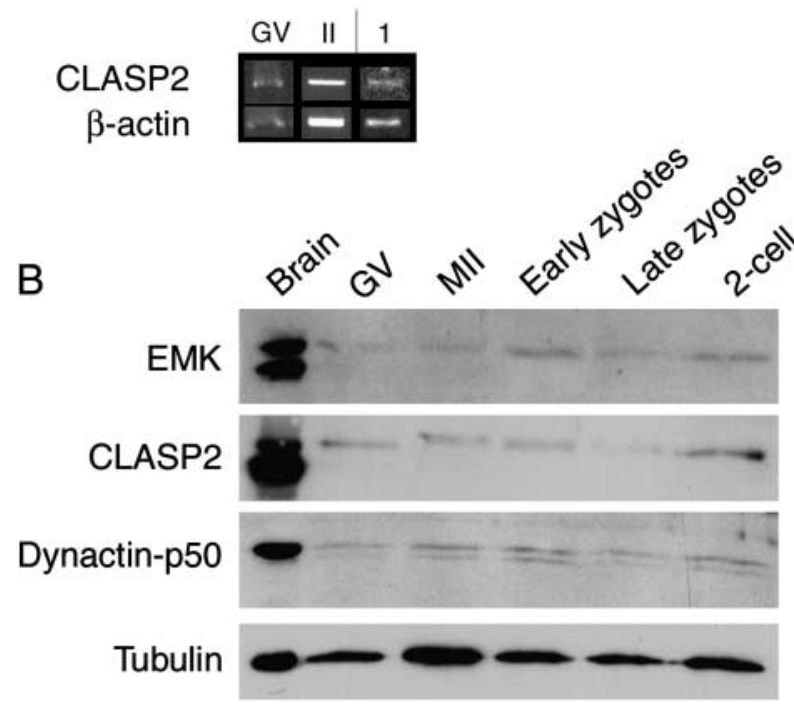

Figure $1 \mathrm{EMK}, \mathrm{CLASP} 2$ and dynactin-p50 are present in mouse oocytes and early embryos. (A) RT-PCR showed the presence of transcripts for EMK and CLASP2 in mouse oocytes and pre-implantation embryos. I= MI, II = MII, cleavage stage numbers indicate the number of cells in the embryo, B = blastocysts. $\beta$-actin levels shown as loading control. Sizes were as expected: $\mathrm{EMK}=258 \mathrm{bp}$,

CLASP2 $=299 \mathrm{bp}$ and $\beta$-actin $=272 \mathrm{bp}$. (B) Western blotting revealed expression of proteins in mouse oocytes and early embryos. Tubulin levels shown as loading control and brain extract loaded in first lane as control for band sizes. All bands shown were the only bands on these clean blots. Sizes were as previously published: EMK $85 \mathrm{kDa}$ (smaller isoform $80 \mathrm{kDa}$ ), CLASP2 $\alpha 170 \mathrm{kDa}$ (smaller isoforms $\beta$ and $\gamma 140 \mathrm{kDa}$ ), dynactin-p50 $50 \mathrm{kDa}$ and tubulin $55 \mathrm{kDa}$.

present in GV and MII oocytes and in zygotes, as shown by RT-PCR (Fig. 1A). Western blotting (Fig. 1B) showed the presence of EMK protein in mouse oocytes from GV to MII stage, and in the zygote and two-cell embryo. Interestingly, two isoforms of EMK were originally isolated (Böhm et al. 1997) and both were seen in the control brain extract lane, but only the higher weight band ( $85 \mathrm{kDa}$ ) could be seen in the mouse oocytes and early embryos. These two isoforms probably arise from differential splicing (Espinosa \& Navarro 1998). The larger, $170 \mathrm{kDa} \alpha$-isoform of CLASP2 (Akhmanova et al. 2001) was detected by western blot in all stages from GV oocytes to two-cell embryos, the brain extract contained the lower weight $\beta$-isoform in addition, as previously reported (Akhmanova et al. 2001). The p50 subunit of dynactin was also present at similar levels in mouse oocytes, zygotes and two-cell embryos, two bands of approximately $50 \mathrm{kDa}$ being detected. This antibody was also specific for an additional intense band of about $85 \mathrm{kDa}$ in oocytes injected with GFP-p50, which was also recognised by an anti-GFP antibody (data not shown).

\section{EMK (PAR-1) localises to the meiotic and mitotic spindles}

Using an antibody raised against the $\mathrm{M}$ and $\mathrm{C}$ domains of mouse EMK (Böhm et al. 1997), it was observed that this homologue of PAR-1 was located in a network pattern in the GV stage oocyte (Fig. 2A) $(100 \%, n=7)$. Comparison with the MT network in the GV oocyte (Fig. 2B) revealed similarity, although incompatibility of fixation conditions prevented co-staining. When the first meiotic spindle formed, EMK accumulated on the spindle (Fig. 2C) (82\%, $n=11$ ). This localisation continued through the first division, with EMK on the MTs of the spindle during anaphase (Fig. 2D) and cytokinesis $(100 \%, n=4)$. Similarly at MII, EMK clearly associated with the spindle (Fig. 2L) $(68 \%, n=44)$. At this stage, EMK co-localisation with MTs was evident, as the peripheral position of the MII spindle allowed better MT fixation. Use of rabbit preimmune serum demonstrated the specificity of this immunostaining (compare Fig. 2J with $2 \mathrm{~K}$ ). In the zygote, EMK was again located in a network pattern, and densely around the nuclear envelopes (Fig. 2E) $(100 \%, n=9)$, a pattern that could also be observed at two-cell stage (Fig. $2 \mathrm{H})(100 \%, n=17)$. EMK accumulated around the condensing chromosomes early in prophase (Fig. $2 \mathrm{H}$ ) $(100 \%, n=4)$, then during the first two embryonic divisions EMK was located in the region of highest MT density, on the spindles and in their vicinity (Fig. $2 \mathrm{~F}, \mathrm{G}$ and I) $(100 \%, n=15)$. Thus EMK localised specifically to the spindles during meiotic and mitotic divisions in mouse oocytes and early embryos. Cytoplasmic staining was also evident at all stages examined, indicating that not all EMK relocates to forming spindles. The accumulation of EMK in areas of most active MT function could be consistent with a role regulating MT dynamics.

\section{CLASP2 localises to spindle poles}

A distinct pattern of CLASP2 localisation was detected in the $\mathrm{Ml}$ stage oocyte, when it accumulated on the spindle poles (Fig. 3A) $(64 \%, n=47)$. This specific localisation was even more apparent at MII spindle poles (Fig. 3B and C) $(63 \%, n=46)$. Throughout meiosis there was also diffuse punctate staining of CLASP2. At both metaphases there was some detectable enrichment on the chromosomes, probably reflecting the kinetochore staining seen in other cell types (e.g. Maiato et al. 2003). The staining pattern was shown to be specific by use of rabbit pre-immune serum as a negative control (compare Fig. $3 \mathrm{C}$ with $3 \mathrm{D}$ ).

\section{Dynactin-p50 localises to kinetochores and a subset of microtubule-organising centres (MTOCs)}

By immunostaining, the p50 subunit of the dynactin complex was shown to localise to dots on the chromosomes 

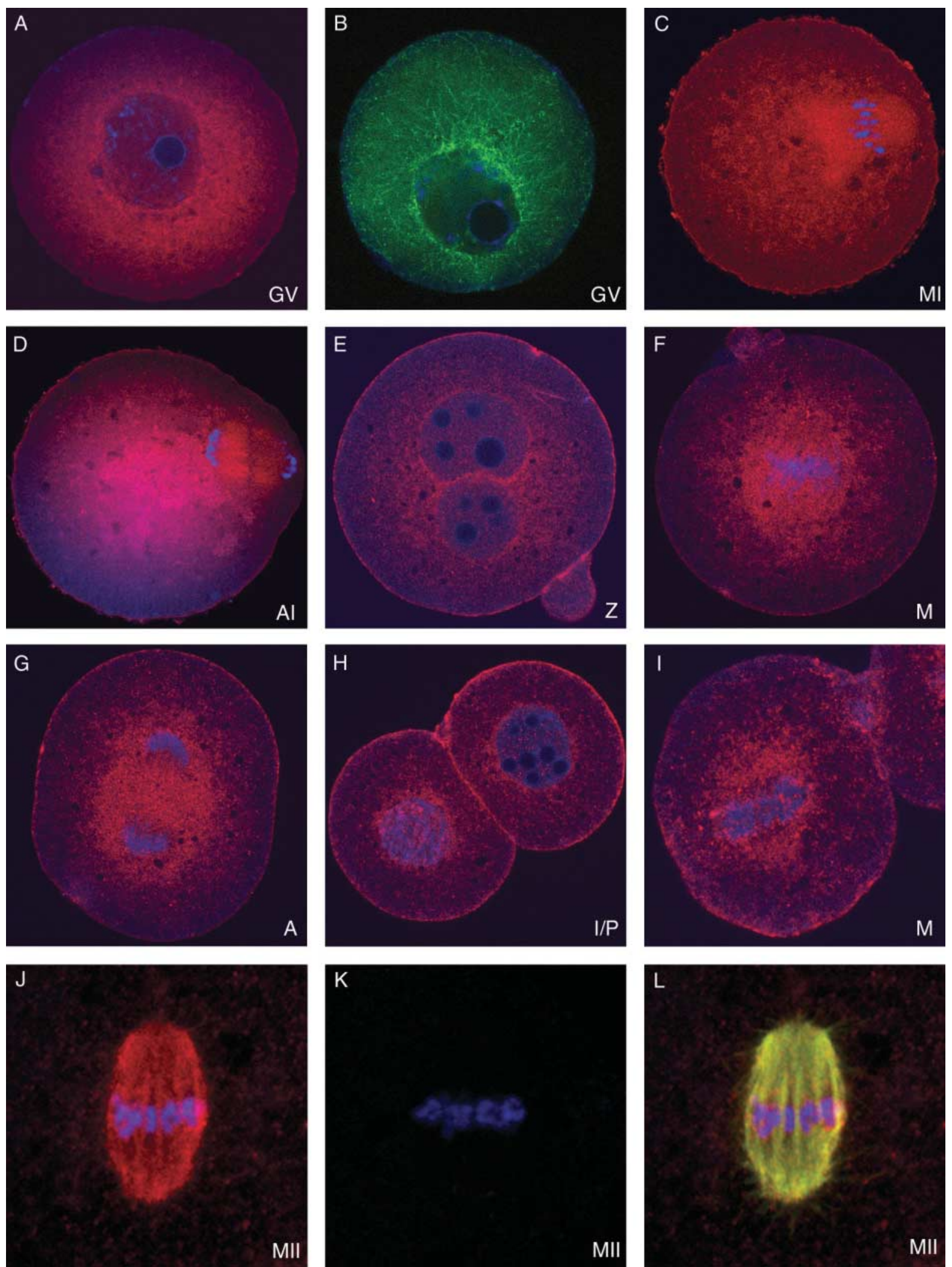

Figure 2 EMK antibody staining of mouse oocytes and embryos specific localisation was seen on meiotic and mitotic spindles. Stages are shown in the bottom right corners. (A) GV stage, (B) GV stage showing tubulin staining, (C) MI, (D) anaphase I (Al), (E) zygote (Z), (F) first mitotic metaphase $(\mathrm{M})$, (G) first mitotic anaphase (A), (H) two-cell stage, left cell early prophase, right cell interphase (I/P), (I) two-cell stage, one cell in metaphase (M), (J) MII spindle, for comparison with (K) control rabbit pre-immune serum on MIl spindle, (L) merged image of EMK and tubulin staining to show colocalisation (yellow) (MII). (A and C-J) red = EMK, (B and $\mathrm{L}$ ) green = tubulin and (K) red = rabbit pre-immune serum; blue $=$ TOTO-3 in all. 

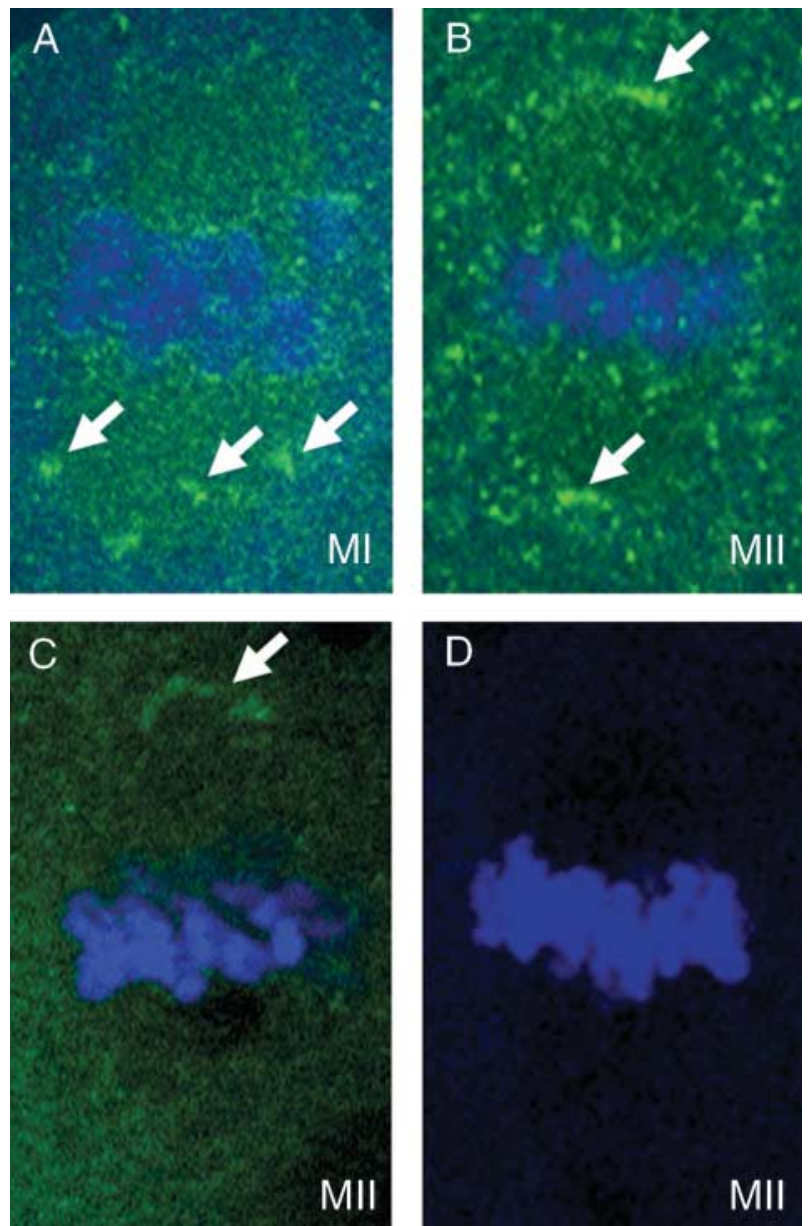

Figure 3 Immunolocalisation of CLASP2 in mouse oocytes. CLASP2 immunostaining revealed accumulation on meiotic spindle poles. Stages are shown in the bottom right corners. Arrows indicate staining on spindle poles. (A) MI, (B, C and D) MII and (D) control rabbit pre-immune serum $(\mathrm{MII})$. $(\mathrm{A}-\mathrm{C})$ green $=\mathrm{CLASP} 2,(\mathrm{D})$ green $=$ rabbit pre-immune serum; blue $=$ TOTO- 3 in all.

during the meiotic (45\% of MI, $n=20 ; 67 \%$ of MII, $n=79)$ and mitotic divisions (100\%, $n=33)$ of mouse oocytes and early embryos (Fig. 4A, E and I). These dots are likely to be the kinetochores, as kinetochore localisation of dynactin has been previously reported in mammalian cell lines (Echeverri et al. 1996). This kinetochore stain was specific, as shown by using purified whole molecule mouse IgG as a negative control (compare Fig. 4A with $4 \mathrm{~B}$ ). In maturing oocytes there are many non-spindle cytoplasmic asters, which persist until just after fertilisation. Dynactin-p50 localised to the centres of these asters (Fig. 4C and D). In zygotes there was slight accumulation of dynactin-p50 around both pronuclei (Fig. 4F), consistent with its proposed role in pronuclear migration in bovine zygotes (Payne et al. 2003). On mitotic spindles, as well as accumulating on kinetochores, dynactin-p50 localised to the spindle poles (Fig. 4G and H) $(100 \%$, $n=16$ ). This kinetochore and spindle pole staining persisted through anaphase and until the nuclei reformed
(Fig. 4J and K) (73\%, $n=15)$. A similar pattern of dynactin-p50 localisation was observed upon microinjection of GFP-p50 mRNA to overexpress this subunit. However, in addition to the kinetochore and cytoplasmic MTOC staining, there was a further large accumulation of dynactinp50 on the poles of the MII spindle (Fig. 4L). This suggests a differential affinity of dynactin-p50 for subsets of MTOCs.

\section{Mouse meiotic spindles have astral microtubules}

Localisation of EMK, CLASP2 and dynactin-p50 was performed in conjunction with tubulin immunostaining. While investigating fixation conditions which best allowed preservation of MT structures, in order that cytoplasmic MTs and MTOCs could be visualised, it was noted that many preparations showed clear astral MTs emanating from both the meiotic spindles (Fig. 5). When fixation in $5 \%$ paraformaldehyde plus Triton X100, Tween 20 and sucrose (see Materials and Methods) was optimal, approximately $70 \%$ (23/33) of meiotic spindles had visible astral MTs. Fixation in $3.7 \%$ paraformaldehyde plus Triton X100 also showed astral MTs in more than one third (11/28) of spindles fixed. These preparations also showed that the barrel-shaped first meiotic spindles can have mutiple MTOCs at the spindle poles, making the spindles more triangular or trapezoid in shape (for example Fig. 5B) $(27 \%$, $n=107)$.

\section{Discussion}

The observed specific accumulation of the PAR-1 homologue EMK, CLASP2 and dynactin-p50 to the meiotic and mitotic spindles suggests that they have functions in formation, maintenance or guidance of the spindles of the mouse oocyte and early embryo. EMK accumulates in the nuclei as soon as chromosomes start to condense and MTs accumulate around them, then EMK becomes associated with spindle MTs. Both CLASP2 and dynactin show specific localisation patterns once the spindle is formed. As in other cell types, dynactin is likely to play multiple roles including participation in the proper alignment of chromosomes at the metaphase plate, by acting at the kinetochores (Echeverri et al. 1996). CLASP2 and dynactin also localise to MTOCs, though to different subsets of these structures: CLASP2 localises to the meiotic spindle poles while dynactin accumulates on non-spindle MTOCs in oocytes and only on spindle poles during mitosis or if overexpressed in oocytes.

The accumulation of EMK on meiotic and mitotic spindles suggests that also in mouse oocytes and embryos it might act as a regulator of MT dynamics, as has been shown in other model systems (Drewes et al. 1997, Ebneth et al. 1999, Shulman et al. 2000, Trinczek et al. 2004). The localisation pattern is, however, different from that seen in C. elegans embryos, Drosophila oocytes and in polarised mammalian epithelial cells, where there is an 

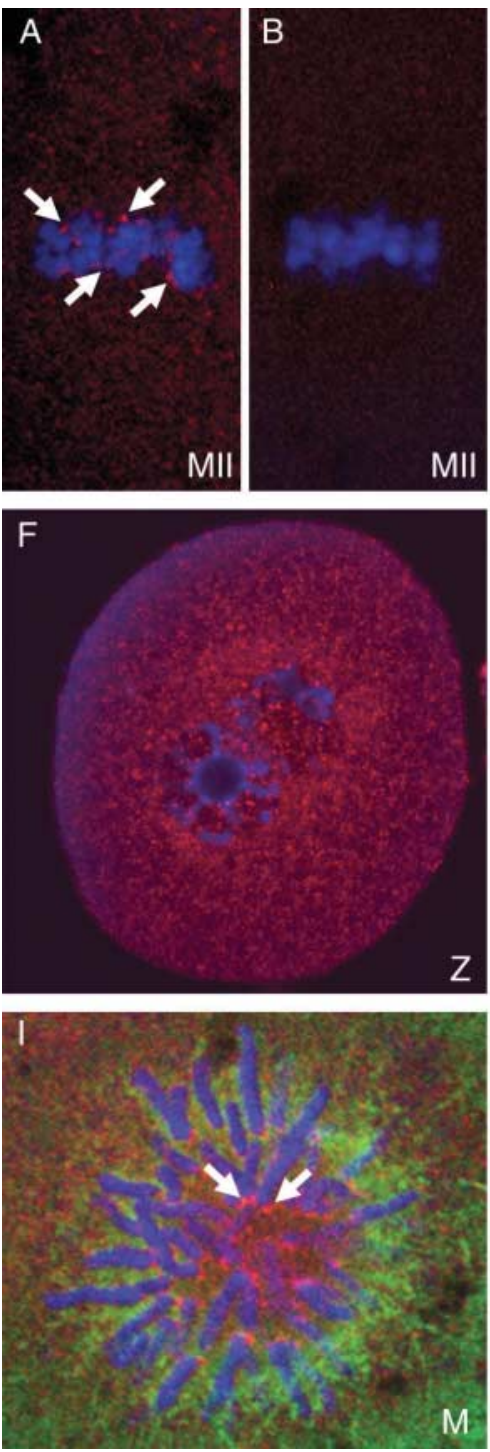
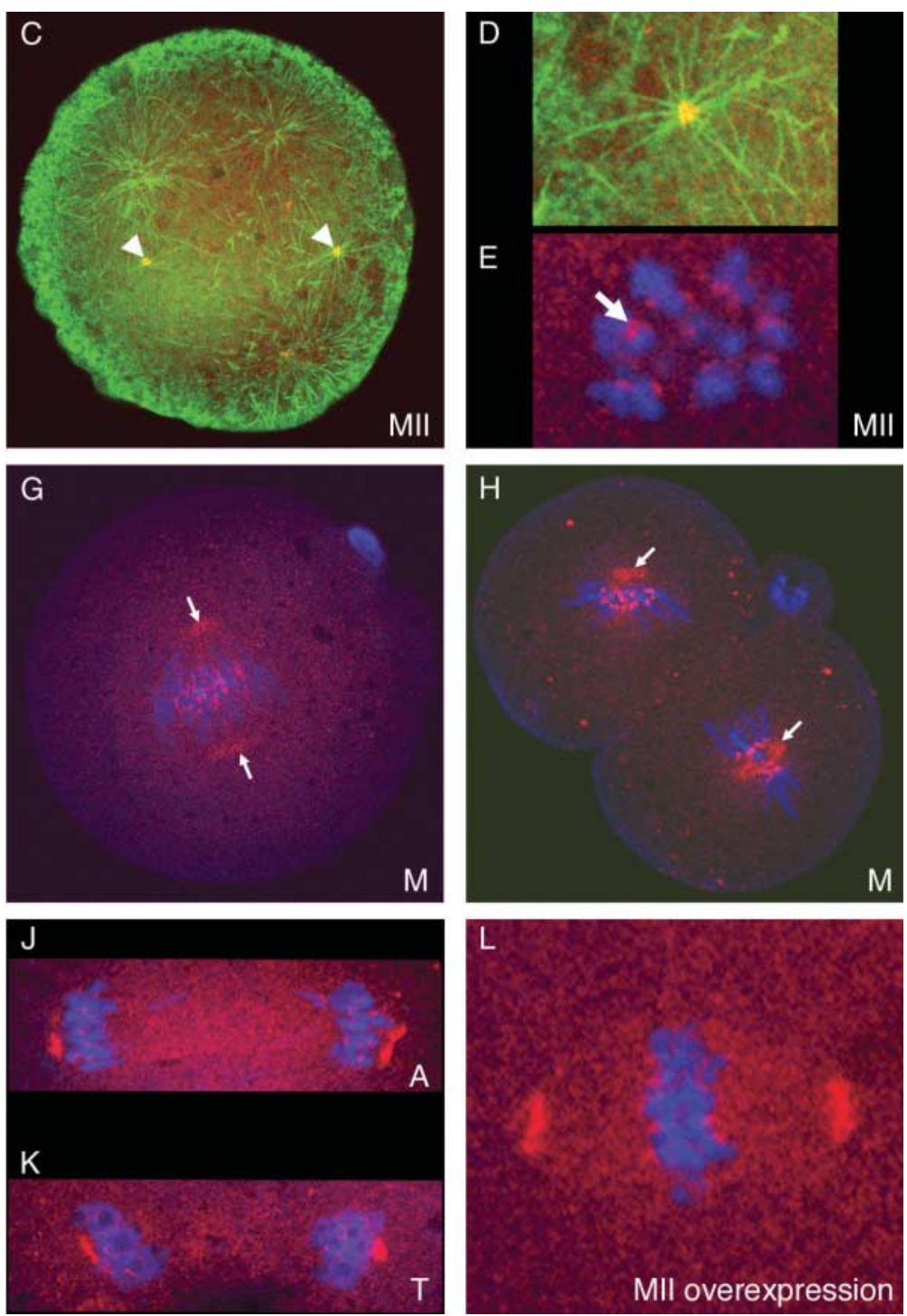
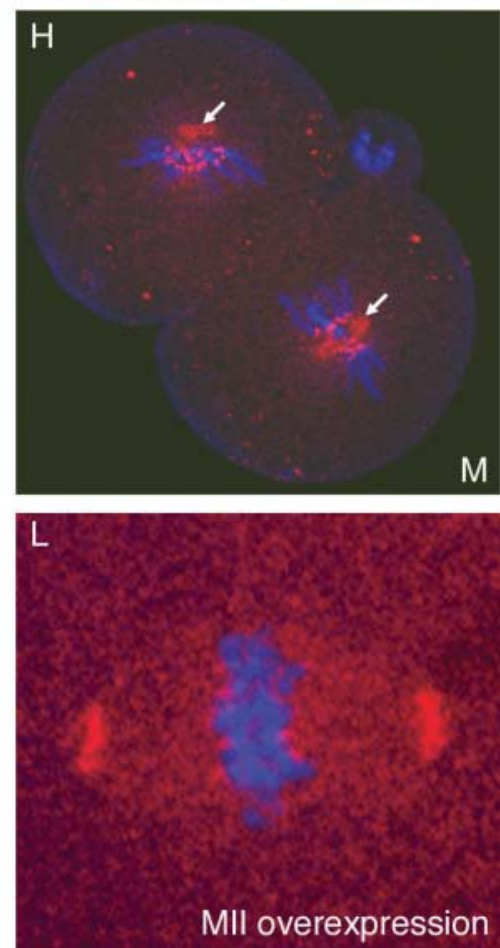

Figure 4 Localisation of dynactin-p50 in mouse oocytes and embryos. Immunostaining with dynactin-p50 antibody showed localisation on kinetochores, in the centres of non-spindle asters and on spindle poles. Stages are shown in the bottom right corners. Large arrows indicate examples of kinetochore staining, arrowheads indicate non-spindle MTOC staining and small arrows indicate mitotic spindle pole staining. (A) MIl spindle, for comparison with (B) control mouse IgG on MII spindle, (C) MII egg, (D) higher magnification of an MII non-spindle aster from (C), showing accumulation of p50 at the MTOC, (E) higher magnification of MIl chromosomes, showing kinetochore staining, (F) zygote (Z), (G) zygote in metaphase $(M)$ showing spindle pole and kinetochore stain, $(H)$ two-cell stage embryo in metaphase $(M)$, (I) higher magnification of 2 nd mitotic spindle showing p50 on kinetochores (M), (J) 2nd mitotic anaphase (A), (K) 2nd mitotic telophase (T) and (L) oocyte injected with p50 mRNA, processed for immunolocalisation of p50, showing localisation to spindle poles and kinetochores. $(\mathrm{A}$ and $\mathrm{C}-\mathrm{L})$ red $=\mathrm{dynactin}-\mathrm{p} 50$, (B) red $=$ mouse $\lg \mathrm{G}$ and $(\mathrm{C}, \mathrm{D}$ and $\mathrm{I})$ green $=$ tubulin; blue $=$ TOTO-3 in all.

accumulation of PAR-1 at a specific region of the cortex (Guo \& Kemphues 1995, Böhm et al. 1997, Shulman et al. 2000). This cortical accumulation creates a region of MT destabilisation, important for localising proteins in these polarised cells (Shulman et al. 2000, for review see Pellettieri \& Seydoux 2002). The differences in localisation suggest that, in the non-epithelial oocyte and early embryo, EMK might be involved in regulating spindle MT dynamics, rather than the dynamics of the MTs which organise the polarisation of the whole cell. The observed localisation on MTs is more like the MT-plus-centrosomal localisation shown for MARK4 (Trinczek et al. 2004). MARK4 kinase activity was shown to have a bundling effect on MTs (Trinczek et al. 2004). Such an effect on the spindle MTs by EMK in mouse oocytes and embryos could be important for proper spindle structure. Recently, another member of the PAR family of proteins, mPARD6, was reported to localise to the mouse meiotic spindles (Vinot et al. 2004). Taken together with the pattern of EMK/PAR-1 localisation shown here, this further suggests that the PAR proteins may have different roles in mouse oocytes because, in other systems where PAR proteins 

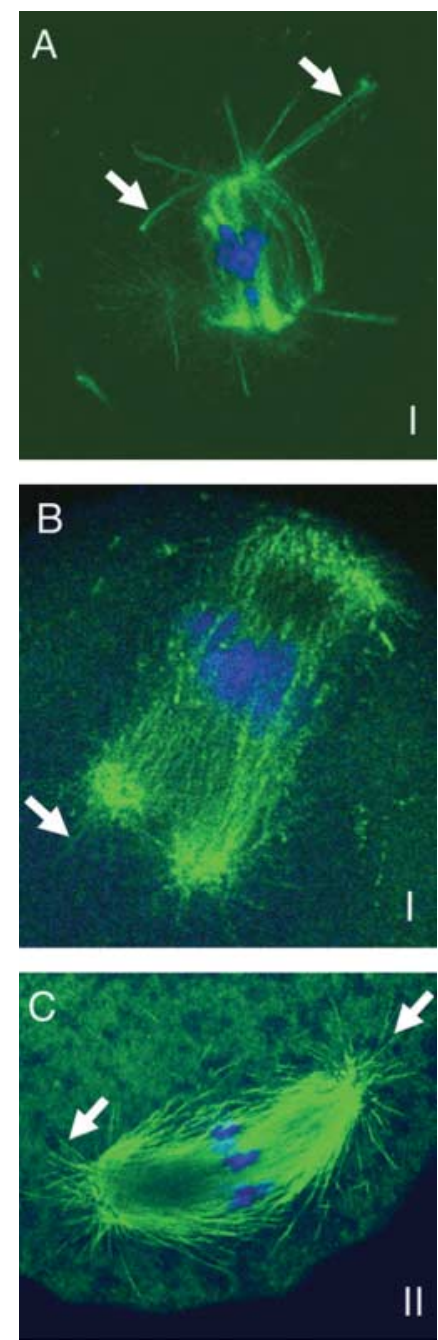

Figure 5 Tubulin immunostaining of mouse meiotic spindles. Astral microtubules clearly visible on both meiotic spindles, examples indicated by arrows. Stages are shown in the bottom right corners. (A and B) meiosis I (I) and (C) second meiotic spindle (II). Green = tubulin; blue $=$ TOTO-3.

have a role in mediating cell polarity, PAR-1 and PAR-6 are found in mutually exclusive locations (for reviews see Ahringer 2003, Macara 2004).

The specific localisation of CLASP2 to spindle poles during meiosis was similar to that reported (in HeLa cells) for CLASP1 (Maiato et al. 2003) and for the Drosophila homologue Mast/Orbit (Inoue et al. 2000, Lemos et al. 2000) during mitosis. In Drosophila, the CLASP homologue has been shown to play a role in chromosome alignment, kinetochore-MT attachment and maintenance of spindle bipolarity (Maiato et al. 2002), and studies in mammalian cells have shown CLASPs to be important for regulating the dynamics of MTs (Akhmanova et al. 2001, Maiato et al. 2003). From the localisation similarities with other cell types, a similar function of CLASP2 during meiosis can also be predicted. It is also possible that CLASP2 has additional functions at the meiotic spindle poles in stabilising the MTs important for direction of spindle migration and/or anchorage at the cortex.

It has been proposed that non-spindle MTOCs present during meiosis are important for the migration of the zygotic pronuclei and for formation of the first mitotic spindles (Maro et al. 1985, Schatten et al. 1986b). The localisation pattern of dynactin shown here supports the view that there are two different groups of MTOCs in the oocyte, spindle and non-spindle MTOCs (Messinger \& Albertini 1991), and that the non-spindle MTOCs mature to form the embryonic spindles, because dynactin was found only on the non-spindle MTOCs in oocytes, then on the spindle MTOCs in embryos. The localisation of p50 to meiotic spindle MTOCs when it was overexpressed points to a differential affinity for spindle and non-spindle MTOCs, with saturation on all MTOCs after overexpression. It is likely that the role of dynactin in pronuclear migration is conserved between bovine (Payne et al. 2003) and mouse zygotes, given the similar localisation around the pronuclear envelopes. This lends further support to the model of progression of MTOCs from the cytoplasm of oocytes to the pronuclear envelopes and then to mitotic spindles (Maro et al. 1985, Schatten et al. 1986b), and suggests that the dynein/dynactin complex could play a role in the process of MTOC organisation.

Our work has focused on proteins with known roles in the regulation of microtubules and found that they have specific localisation on the spindles of mouse oocytes and early embryos. Each of the proteins studied here has been previously shown to bind or regulate other microtubuleassociated proteins. PAR-1 homologues regulate the affinity of some microtubule-associated proteins for MTs. CLASPs and the dynein/dynactin complex are part of the ever-growing family of plus end-associated proteins, which in many cases stabilise growing MTs. Our demonstration of astral MTs on meiotic spindles suggests that stabilisation of plus ends may be important for positioning of these spindles. Interactions between the astral MTs and the cell cortex may play roles alongside the actindependent migration of the first meiotic spindle to the cortex, and may be involved in tethering the second spindle during the prolonged metaphase arrest. As the meiotic divisions create an asymmetry in the egg which relates to later patterning of fertilised embryos (Gardner 1997, Weber et al. 1999, Ciemerych et al. 2000, Plusa et al. 2002, Piotrowska-Nitsche \& Zernicka-Goetz 2005, Piotrowska-Nitsche et al. 2005), the study of meiotic asymmetry is important for further understanding of early embryonic development.

\section{Acknowledgements}

We would like to thank Jie Na, Berenika Plusa and Alex Sossick for technical assistance with immunostaining and confocal microscopy, and Teymuras Kurzchalia, Anna Akhmanova and Tony Hyman for gifts of antibodies and constructs. This work was supported by a BBSRC project grant awarded to $M$ 
Z-G and an MRC studentship awarded to C A M. M Z-G is a Wellcome Senior Research Fellow. The authors declare that there is no conflict of interest that would prejudice the impartiality of this scientific work.

\section{References}

Ahringer J 2003 Control of cell polarity and mitotic spindle positioning in animal cells. Current Opinion in Cell Biology 15 73-81.

Akhmanova A, Hoogenraad CC, Drabek K, Stepanova T, Dortland B, Verkerk T, Vermeulen W, Burgering BM, De Zeeuw $\mathrm{CI}$, Grosveld F \& Galjart N 2001 Clasps are CLIP-115 and -170 associating proteins involved in the regional regulation of microtubule dynamics in motile fibroblasts. Cell 104 923-935.

Albertini DF \& Barrett SL 2004 The developmental origins of mammalian oocyte polarity. Seminars in Cell and Developmental Biology 15 599-606.

Böhm H, Brinkmann V, Drab M, Henske A \& Kurzchalia TV 1997 Mammalian homologues of $C$. elegans PAR-1 are asymmetrically localized in epithelial cells and may influence their polarity. Current Biology 7 603-606.

Busson S, Dujardin D, Moreau A, Dompierre J \& De Mey JR 1998 Dynein and dynactin are localized to astral microtubules and at cortical sites in mitotic epithelial cells. Current Biology 8 541-544.

Ciemerych MA, Mesnard D \& Zernicka-Goetz M 2000 Animal and vegetal poles of the mouse egg predict the polarity of the embryonic axis, yet are nonessential for development. Development 127 3467-3474.

Drewes G, Ebneth A, Preuss U, Mandelkow EM \& Mandelkow E 1997 MARK, a novel family of protein kinases that phosphorylate microtubule-associated proteins and trigger microtubule disruption. Cell 89 297-308.

Dujardin DL \& Vallee RB 2002 Dynein at the cortex. Current Opinion in Cell Biology $\mathbf{1 4} 44-49$.

Ebneth A, Drewes G, Mandelkow EM \& Mandelkow E 1999 Phosphorylation of MAP2C and MAP4 by MARK kinases leads to the destabilization of microtubules in cells. Cell Motility and the Cytoskeleton 44 209-224.

Echeverri CJ, Paschal BM, Vaughan KT \& Vallee RB 1996 Molecular characterization of the 50-kDa subunit of dynactin reveals function for the complex in chromosome alignment and spindle organization during mitosis. Journal of Cell Biology 132 617-633.

Espinosa L \& Navarro E 1998 Human serine/threonine protein kinase EMK1: genomic structure and cDNA cloning of isoforms produced by alternative splicing. Cytogenetics and Cell Genetics 81 278-282.

Gardner RL 1997 The early blastocyst is bilaterally symmetrical and its axis of symmetry is aligned with the animal-vegetal axis of the zygote in the mouse. Development 124 289-301.

Gray D, Plusa B, Piotrowska K, Na J, Tom B, Glover DM \& ZernickaGoetz M 2004 First cleavage of the mouse embryo responds to change in egg shape at fertilization. Current Biology 14 397-405.

Guo S \& Kemphues KJ 1995 par-1, a gene required for establishing polarity in C. elegans embryos, encodes a putative Ser/Thr kinase that is asymmetrically distributed. Cell 81 611-620.

Inglis JD, Lee M \& Hill RE 1993 Emk, a protein kinase with homologs in yeast maps to mouse chromosome 19. Mammalian Genome 4 401-403.

Inoue YH, do Carmo Avides M, Shiraki M, Deak P, Yamaguchi M, Nishimoto Y, Matsukage A \& Glover DM 2000 Orbit, a novel microtubule-associated protein essential for mitosis in Drosophila melanogaster. Journal of Cell Biology 149 153-166.

Kaltschmidt JA \& Brand AH 2002 Asymmetric cell division: microtubule dynamics and spindle asymmetry. Journal of Cell Science $1152257-2264$.

Leader B, Lim H, Carabatsos MJ, Harrington A, Ecsedy J, Pellman D, Maas R \& Leder P 2002 Formin-2, polyploidy, hypofertility and positioning of the meiotic spindle in mouse oocytes. Nature Cell Biology 4 921-928.

Lemos CL, Sampaio P, Maiato H, Costa M, Omel'yanchuk LV, Liberal V \& Sunkel CE 2000 Mast, a conserved microtubule-associated protein required for bipolar mitotic spindle organization. $E M B O$ Journal $193668-3682$.

Longo FJ \& Chen DY 1985 Development of cortical polarity in mouse eggs: involvement of the meiotic apparatus. Developmental Biology 107 382-394.

Macara IG 2004 Parsing the polarity code. Nature Reviews in Molecular Cell Biology 5 220-231.

McNally FJ 2001 Cytoskeleton: CLASPing the end to the edge. Current Biology 11 R477-R480.

Maiato $\mathbf{H}$, Sampaio $\mathbf{P}$, Lemos $\mathrm{CL}$, Findlay J, Carmena M, Earnshaw WC \& Sunkel CE 2002 MAST/Orbit has a role in microtubulekinetochore attachment and is essential for chromosome alignment and maintenance of spindle bipolarity. Journal of Cell Biology 157 749-760.

Maiato H, Fairley EA, Rieder CL, Swedlow JR, Sunkel CE \& Earnshaw WC 2003 Human CLASP1 is an outer kinetochore component that regulates spindle microtubule dynamics. Cell 113 891-904.

Maro B \& Verlhac MH 2002 Polar body formation: new rules for asymmetric divisions. Nature Cell Biology 4 E281-E283.

Maro B, Howlett SK \& Webb M 1985 Non-spindle microtubule organizing centers in metaphase Il-arrested mouse oocytes. Journal of Cell Biology 101 1665-1672.

Maro B, Johnson MH, Webb M \& Flach G 1986 Mechanism of polar body formation in the mouse oocyte: an interaction between the chromosomes, the cytoskeleton and the plasma membrane. Journal of Embryology and Experimental Morphology 92 11-32.

Messinger SM \& Albertini DF 1991 Centrosome and microtubule dynamics during meiotic progression in the mouse oocyte. Journal of Cell Science 100 289-298.

Mimori-Kiyosue Y \& Tsukita S 2003 'Search-and-capture' of microtubules through plus-end-binding proteins (+TIPs). Journal of Biochemistry (Tokyo) 134 321-326.

Nagy A, Gertsenstein M, Vintersten K \& Behringer R 2003 Manipulating the mouse embryo, A Laboratory Manual. $3^{\text {rd }}$ edn. New York, Cold Spring Harbor Press.

O'Connell CB \& Wang YL 2000 Mammalian spindle orientation and position respond to changes in cell shape in a dynein-dependent fashion. Molecular Biology of the Cell 11 1765-1774.

Payne C, Rawe V, Ramalho-Santos J, Simerly C \& Schatten G 2003 Preferentially localized dynein and perinuclear dynactin associate with nuclear pore complex proteins to mediate genomic union during mammalian fertilization. Journal of Cell Science $\mathbf{1 1 6}$ 4727-4738.

Pellettieri J \& Seydoux G 2002 Anterior-posterior polarity in C. elegans and Drosophila - PARallels and differences. Science 298 1946-1950.

Piotrowska-Nitsche K \& Zernicka-Goetz M 2005 Spatial arrangement of individual 4-cell stage blastomeres and the order in which they are generated correlate with blastocyst pattern in the mouse embryo. Mechanisms of Development 122 487-500.

Piotrowska-Nitsche K, Perea-Gomez A, Haraguchi S \& ZernickaGoetz M 2005 Four-cell stage mouse blastomeres have different developmental properties. Development 132 479-490.

Plusa B, Grabarek JB, Piotrowska K, Glover DM \& ZernickaGoetz M 2002 Site of the previous meiotic division defines cleavage orientation in the mouse embryo. Nature Cell Biology 4 811-815.

Plusa B, Hadjantonakis A-K, Gray D, Piotrowska-Nitsche K, Jedrusik A , Papaionnou VE, Glover DM \& Zernicka-Goetz M 2005 The first cleavage of the mouse zygote predicts the blastocyst axis. Nature 434 391-395.

Sanfins A, Lee GY, Plancha CE, Overstrom EW \& Albertini DF 2003 Distinctions in meiotic spindle structure and assembly during in vitro and in vivo maturation of mouse oocytes. Biology of Reproduction 69 2059-2067. 
Sanfins A, Plancha CE, Overstrom EW \& Albertini DF 2004 Meiotic spindle morphogenesis in in vivo and in vitro matured mouse oocytes: insights into the relationship between nuclear and cytoplasmic quality. Human Reproduction 19 2889-2899.

Schatten H, Cheney R, Balczon R, Willard M, Cline C, Simerly C \& Schatten G 1986a Localization of fodrin during fertilization and early development of sea urchins and mice. Developmental Biology 118 457-466.

Schatten H, Schatten G, Mazia D, Balczon R \& Simerly C 1986b Behavior of centrosomes during fertilization and cell division in mouse oocytes and in sea urchin eggs. PNAS 83 105-109.

Schuyler SC \& Pellman D 2001 Microtubule 'plus-end-tracking proteins': the end is just the beginning. Cell 105 421-424.

Segal M \& Bloom K 2001 Control of spindle polarity and orientation in Saccharomyces cerevisiae. Trends in Cell Biology 11 160-166.

Sheeman B, Carvalho P, Sagot I, Geiser J, Kho D, Hoyt MA \& Pellman D 2003 Determinants of S. cerevisiae dynein localization and activation: implications for the mechanism of spindle positioning. Current Biology 13 364-372.

Shulman JM, Benton R \& St Johnston D 2000 The Drosophila homo$\log$ of C. elegans PAR-1 organizes the oocyte cytoskeleton and directs oskar mRNA localization to the posterior pole. Cell 101 $377-388$.

Simerly C, Nowak G, de Lanerolle P \& Schatten G 1998 Differential expression and functions of cortical myosin IIA and IIB isotypes during meiotic maturation, fertilization, and mitosis in mouse oocytes and embryos. Molecular Biology of the Cell 9 2509-2525.

Skop AR \& White JG 1998 The dynactin complex is required for cleavage plane specification in early Caenorhabditis elegans embryos. Current Biology 8 1110-1116.

Szöllösi D, Calarco P \& Donahue RP 1972 Absence of centrioles in the first and second meiotic spindles of mouse oocytes. Journal of Cell Science 11 521-541.

Trinczek B, Brajenovic M, Ebneth A \& Drewes G 2004 MARK4 is a novel microtubule-associated proteins/microtubule affinity-regulat- ing kinase that binds to the cellular microtubule network and to centrosomes. Journal of Biological Chemistry 279 5915-5923.

Van Blerkom J \& Bell H 1986 Regulation of development in the fully grown mouse oocyte: chromosome-mediated temporal and spatial differentiation of the cytoplasm and plasma membrane. Journal of Embryology and Experimental Morphology 93 213-238.

Verlhac MH, Lefebvre C, Guillaud P, Rassinier P \& Maro B 2000 Asymmetric division in mouse oocytes: with or without Mos. Current Biology 10 1303-1306.

Vinot S, Le T, Maro B \& Louvet-Vallee S 2004 Two PAR6 proteins become asymmetrically localized during establishment of polarity in mouse oocytes. Current Biology 14 520-525.

Weber RJ, Pedersen RA, Wianny F, Evans MJ \& Zernicka-Goetz M 1999 Polarity of the mouse embryo is anticipated before implantation. Development $1265591-5598$.

Wittmann T \& Hyman T 1999 Recombinant p50/dynamitin as a tool to examine the role of dynactin in intracellular processes. Methods in Cell Biology 61 137-143.

Zernicka-Goetz M, Pines J, Ryan K, Siemering KR, Haseloff J, Evans MJ \& Gurdon JB 1996 An indelible lineage marker for Xenopus using a mutated green fluorescent protein. Development 122 $3719-3724$.

Zernicka-Goetz M, Pines J, McLean Hunter S, Dixon JP, Siemering KR, Haseloff J \& Evans MJ 1997 Following cell fate in the living mouse embryo. Development 124 1133-1137.

Received 14 January 2005

First decision 1 March 2005

Revised manuscript received 20 May 2005

Accepted 1 June 2005 